27(1), 13-20

\title{
Maximum Tolerated Dose Estimation by Stopping Rule and SM3 Design in a Phase I Clinical Trial
}

\author{
Byoungchan $\operatorname{Kim}^{a} \cdot$ Dongjae $\operatorname{Kim}^{a, 1}$ \\ ${ }^{a}$ Department of Biostatistics, The Catholic University of Korea \\ (Received October 15, 2013; Revised November 15, 2013; Accepted November 15, 2013)
}

\begin{abstract}
Phase I Clinical Trials estimate a Maximum Tolerated Dose(MTD). In this paper, an MTD estimation method applied stopping rule is proposed for Phase I Clinical Trials. The suggested MTD estimation method is compared to the Continual Reassessment Method(CRM) method using a Monte Carlo simulation study.
\end{abstract}

Keywords: Phase I clinical trial, maximum tolerated dose, stopping rule.

\section{1. 서론}

임상시험(Clinical Trial)이란 의약품을 개발 및 시판하기에 앞서 그 물질의 안정성과 치료효용성을 증 명할 목적으로 해당 약물의 체내분포, 대사 및 배설, 약리효과와 임상적 효과를 확인하고 부작용 등을 알아보기 위해 사람을 대상으로 실시하는 시험을 말한다. 임상시험의 첫 단계인 제 1 상 임상시험은 사 람을 대상으로 처음 실시하며, 신약후보물질의 안전성을 평가하고 약물동력학(pharmacokinetics) 및 약력학(pharmacodynamics)을 연구하기 위해 환자들을 대상으로 독성 및 부작용 등 반응을 관찰하는 단계이다. 제 1 상 임상시험의 목적은 피험자가 견딜 수 있는 최대의 용량인 최대허용용량(Maximum Tolerated Dose; MTD)을 결정하는 것이며 적은 수의 피험자를 통해 $\mathrm{MTD}$ 를 정확히 결정해야 한다. 최대허용용량의 결정은 목표로 정한 독성 반응율을 초과하지 않는 복용량의 추정이며 (Chevret, 1993), 사람에게 허용할 수 있는 독성수준에서 최대 효능을 가진 용량 범위의 추정 (O'Quigley와 Chevret, 1991)이다. 여기서 MTD는 독성이 나타나지 않는 용량 범위 중에서 최대 복용량을 뜻하거나, 또는 독성반응이 나타나는 용량 범위 중에서 최소 복용량을 뜻하고 (Korn 등, 1994; Goodman, 1995) 구 체적으로는 용량에 따른 독성 반응율을 표현한 백분위수에서 대략 33 분위수를 MTD로 정하고 있다 (Storer, 1989).

기존의 MTD를 결정하는 추정방법은 Dixon과 $\operatorname{Mood}$ (1948)에 의해 제안된 DM방법이 있다. 이 방법 은 피험자 1 명의 독성반응에 의해 실험이 진행되므로 계획이 단순하고 실험 전에 피험자수를 결정하는 것으로 실험 전에 준비가 끝나지만 목표독성확률에 해당하는 $\mathrm{MTD}$ 를 정확하게 제시하지 못하거나 일부 피험자는 치료효과가 없는 낮은 용량수준에 할당되고 있는 문제점이 있다.

멈춤규칙에 의한 MTD 추정법은 Korn 등 (1994)이 제안한 표준방법(Standard Method; SM)이 있 다. 표준방법에는 SM3와 SM6 계획이 있는데 이 표준방법들은 $33 \%$ 독성반응율에 해당하는 $\mathrm{MTD}$ 를

\footnotetext{
${ }^{1}$ Corresponding author: Professor, Department of Biostatistics, The Catholic University of Korea, BanpoDong, Seocho-Gu, Seoul 137-701, Korea. E-mail: djkim@catholic.ac.kr
} 
추정하기위해 각 용량수준에 기본적으로 3 명의 피험자가 배정되는 계획이다. Goodman 등 (1995)은 $\mathrm{SM} 3$ 방법이 미국에서 주로 사용되고 있는 표준방법이라 설명하고 있다. SM방법은 최대 허용용량에서 의 독성발생확률이 $33 \%$ 에 가까울 것이라는 막연한 추측과 최종적으로 얻어진 최대허용용량의 독성비율 이 실험 전에 잡은 목표독성확률에 가까워짐을 보장할 수는 없다는 점, 첫 용량수준에서 멈춤규칙의 조 건이 만족되어 시행이 종료되는 경우와 마지막 용량수준까지도 Stopping rule이 만족되지않아 시행이 종료되지 않는 경우에는 $\mathrm{MTD}$ 의 추정이 불가능하고 반응이 나타날 때까지 실험을 해야 되므로 종료기 간이 불확실하다는 단점이 있다.

최근 제 1상 임상시험에서는 $\mathrm{SM}$ 방법을 대체할 방법으로 $\mathrm{CRM}$ (Continual Reassessment Method)이 많이 사용되어지고 있다. CRM은 미리 고정된 피험자 수를 통해 피험자 한 명씩을 시험하는 방법으로 시험 전에 피험자에게서 독성이 발생할 것이라 생각하는 목표독성율을 정하고 이전의 피험자에게서 얻 어진 독성결과를 이용하여 현재의 dose-toxicity 곡선에 대한 정보를 수정하여 다음 피험자에게 투여할 용량을 결정하는 축차적 MTD추정법이다 (Kim과 Kil, 2009). Kang (2002)은 CRM방법이 현실적으 로 사용되기에 여러가지 문제점이 있음을 지적하였다. 첫째는 최초의 용량수준을 모수의 사전분포에만 근거하여 결정하였고, 종종 가장 낮은 용량보다 높은 용량에 환자를 배정하기도 한다. 두 번째는 용량 이 올라갈 때, 아무런 제약없이 수정된 용량독성곡선과 사후분포를 이용하여 결정되는 점이다. 세 번째 는 실험에 지나치게 많은 시간이 소요된다는 점을 지적하였다. 이러한 문제점을 보완하기 위해 수정된 CRM방법이 제안되었다 (Faries, 1994; Goodman, 1995; Kang, 2002).

임상시험에 따라 최대허용용량(MTD)의 목표독성확률을 다르게 설정할 수 있다. Goodman (1995), Storer (1989)는 목표독성확률을 $33 \%$ 로 추정하며, O'Quigley와 Chevret (1991)는 $25 \%$ 로 추정한 다. Park (1999)는 일반적인 임상시험에서 목표독성확률을 최소 $20 \%$, 최대 $33 \%$ 로 추정한다. Park (1999)는 Phase 1에서 최대허용용량(MTD) 추정은 오래 전부터 연구되어 왔으며 각 방법들에 대해서 많은 장단점이 제시되었으나 아직까지 어떤 방법이 가장 좋다는 결론을 내리지 못한 상태로 계속 연구되 고 있다. 그 이유 중 하나는 '모의실험'에 의존한 과거 여러 연구의 독성반응율 곡선, 시작용량, 용량단 계가 서로 다르고, 여러 표준방법 중에서도 각 논문이 연구하기 위해 선택한 표준방법이 또한 다르기 때 문에 즉각적인 비교가 어려워서였다 (Park, 1999).

기존의 SM방법과 $\mathrm{CRM}$ 방법의 비교를 쓴 논문들에서는 $\mathrm{SM}$ 방법에서 주장하는 목표독성확률 $33 \%$ 를 기 준으로 방법들을 비교하였지만, CRM방법에서 주장하는 $25 \%$ 를 기준으로 방법들을 비교한 논문은 없었 다. 본 논문에서는 SM방법의 멈춤 규칙을 쓰되 막연한 추측으로 쓰이는 목표독성확률 $33 \%$ 을 이용하 지 않고 $\mathrm{CRM}$ 방법에 주로 쓰이는 $25 \%$ 를 목표독성확률로 이용해 $\mathrm{MTD}$ 를 추정하는 방법을 제안하였다. 이 방법은 3 명의 피험자를 배정하는 SM방법과 달리 4 명의 피험자를 배정한다. 4 명의 피험자로부터 동 일한 용량에 독성반응이 0 명일 경우 용량 증가시키고, 독성반응이 2 명 이상일 경우 용량 증가는 중지한 다. 독성반응이 1 명일 경우 동일한 용량에 1 명을 추가한다. 5 명의 피험자로부터 독성반응이 1 명일 경 우 용량을 증가시키고, 독성반응이 2 명 이상일 경우 용량 증가는 중지한다. 이 방법은 SM방법에 비해 $\mathrm{MTD}$ 결정에 보수적이고 적은 피험자 수로 실험이 종료될 것이며, $\mathrm{CRM}$ 방법에 비해 짧은 실험시간과 높은 안전성이 예상된다.

\section{2. 제안된 MTD 추정방법}

현재 가장 많이 사용되는 SM3방법은 세 명의 피험자를 배정하여 피험자들의 독성반응이 멈춤 규칙의 조건을 만족하면 시험을 종료하고 $\mathrm{MTD}$ 를 제시하는 방법이다. 먼저 피험자 3 명씩 시험하여 독성반응 이 2 명 이상일 경우 시험을 종료하고 한 단계 낮은 용량으로 $\mathrm{MTD}$ 를 결정하고, 독성반응이 1 명일 경우 같은 복용량에 3 명을 추가해 총 6 명 중 2 명 이상 독성반응을 보일 경우 시험을 종료하고 역시 한 한계 


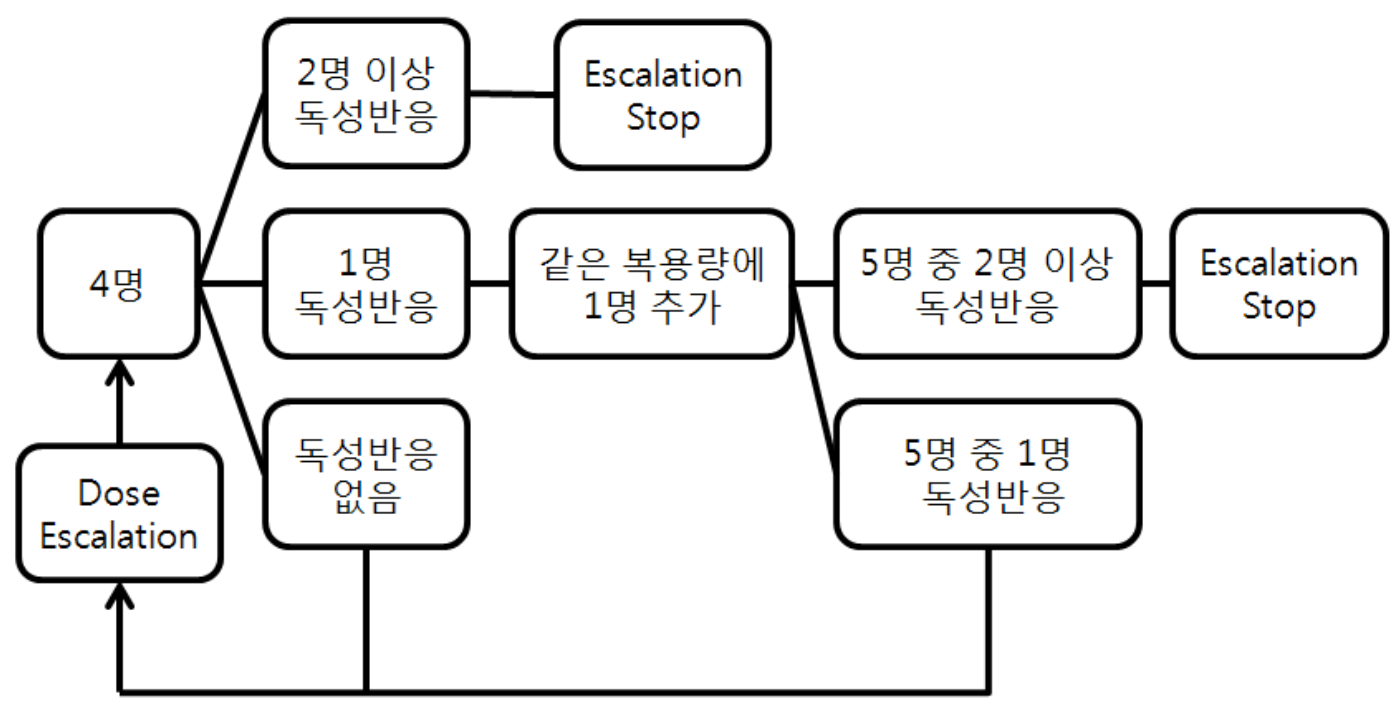

Figure 2.1. Process of $\mathrm{BC} 4$ method

낮은 용량으로 MTD를 결정한다. 또 6 명 중 1 명만이 독성반응을 나타냈을 경우와 처음 피험자 3 명에서 아무도 독성반응이 나타나지 않았을 경우에는 다음 피험자 군에게 한 단계 높은 용량을 적용한다. 첫 용 량수준에서 멈춤 규칙의 조건이 만족되어 시행이 종료되는 경우와 마지막 용량수준까지도 멈춤 규칙이 만족하지 않아 시행이 종료되지 않는 경우에는 MTD의 추정이 불가능하다.

본 논문에서 새로 제안한 $\mathrm{BC} 4$ 방법은 목표독성확률이 $33 \%$ 인 SM3방법을 응용하되 목표독성확률을 $25 \%$ 으로 적용시켜 $\mathrm{MTD}$ 를 추정하는 방법이다. 우선 4 명의 피험자를 배정하고 이 4 명의 피험자로부터 동일한 용량에 독성반응이 0 명일 경우 용량 증가시키고, 독성반응이 2 명 이상일 경우 용량 증가는 중지 한다. 독성반응이 1 명일 경우 동일한 용량에 1 명을 추가한다. 5 명의 피험자로부터 독성반응이 1 명일 경우 용량을 증가시키고, 독성반응이 2 명 이상일 경우 용량 증가는 중지한다. 독성반응을 보이는 경우 실험은 종료된다. 시험이 종료한 경우 Korn 등 (1994)은 MTD를 허용할 수 없는(unacceptable) 독성 용량수준으로 정의하고 있으며, 이러한 정의에 의해 실험을 종료한 후 한 단계 낮은 용량수준을 $\mathrm{MTD}$ 로 정한다. SM3방법과 마찬가지로 첫 용량수준에서 멈춤 규칙의 조건이 만족되어 시행이 종료되는 경우와 마지막 용량수준까지도 멈춤 규칙이 만족하지 않아 시행이 종료되지 않는 경우에는 $\mathrm{MTD}$ 의 추정이 불 가능하다. 제안된 MTD 추정방법의 과정을 Figure 2.1 로 나타내었다.

\section{3. 모의실험과 그 결과}

모의실험은 본 논문에서 제안한 멈춤 규칙을 이용한 $\mathrm{BC} 4$ 방법과 축차적인 방법인 $\mathrm{CRM}$ 방법 간의 비교 를 위해 실시하였다. 제 1 상 임상시험의 모의실험에서 복용량 수준은 6 단계가 많이 사용되지만 본 논문 에서는 좀 더 세밀한 8단계로 지정하였다. 모의실험에서 사용한 dose toxicity curves는 Park (1999)와 $\mathrm{Ahn}$ (1998)에서 사용한 곡선을 기초로 8단계의 복용량수준으로 수정하여 사용하였다. 모의실험에서 사용한 각 복용량 수준의 독성반응율은 Table 3.1과 Figure 3.1로 나타내었다. 곡선1은 용량수준이 비 교적 균일하게 분포하는 경우이고, 곡선 $2,3,4,5,6$ 은 독성 반응율이 낮았다가 특정용량수준에서 급격 
Table 3.1. Dose toxicity curves in simulation study (\%)

\begin{tabular}{ccccccccc}
\hline Dose level & 곡선1 & 곡선2 & 곡선3 & 곡선4 & 곡선5 & 곡선6 & 곡선7 & 곡선8 \\
\hline 1 & 5 & 2 & 1 & 1 & 1 & 5 & 22 & 15 \\
2 & 10 & 4 & 1 & 3 & 2 & 25 & 32 & 25 \\
3 & 25 & 33 & 5 & 5 & 3 & 50 & 41 & 35 \\
4 & 35 & 67 & 10 & 32 & 4 & 60 & 48 & 45 \\
5 & 50 & 80 & 25 & 55 & 15 & 70 & 54 & 55 \\
6 & 70 & 85 & 80 & 75 & 25 & 80 & 69 & 65 \\
7 & 80 & 90 & 90 & 82 & 50 & 90 & 80 & 75 \\
8 & 90 & 93 & 95 & 95 & 65 & 95 & 89 & 85 \\
\hline
\end{tabular}

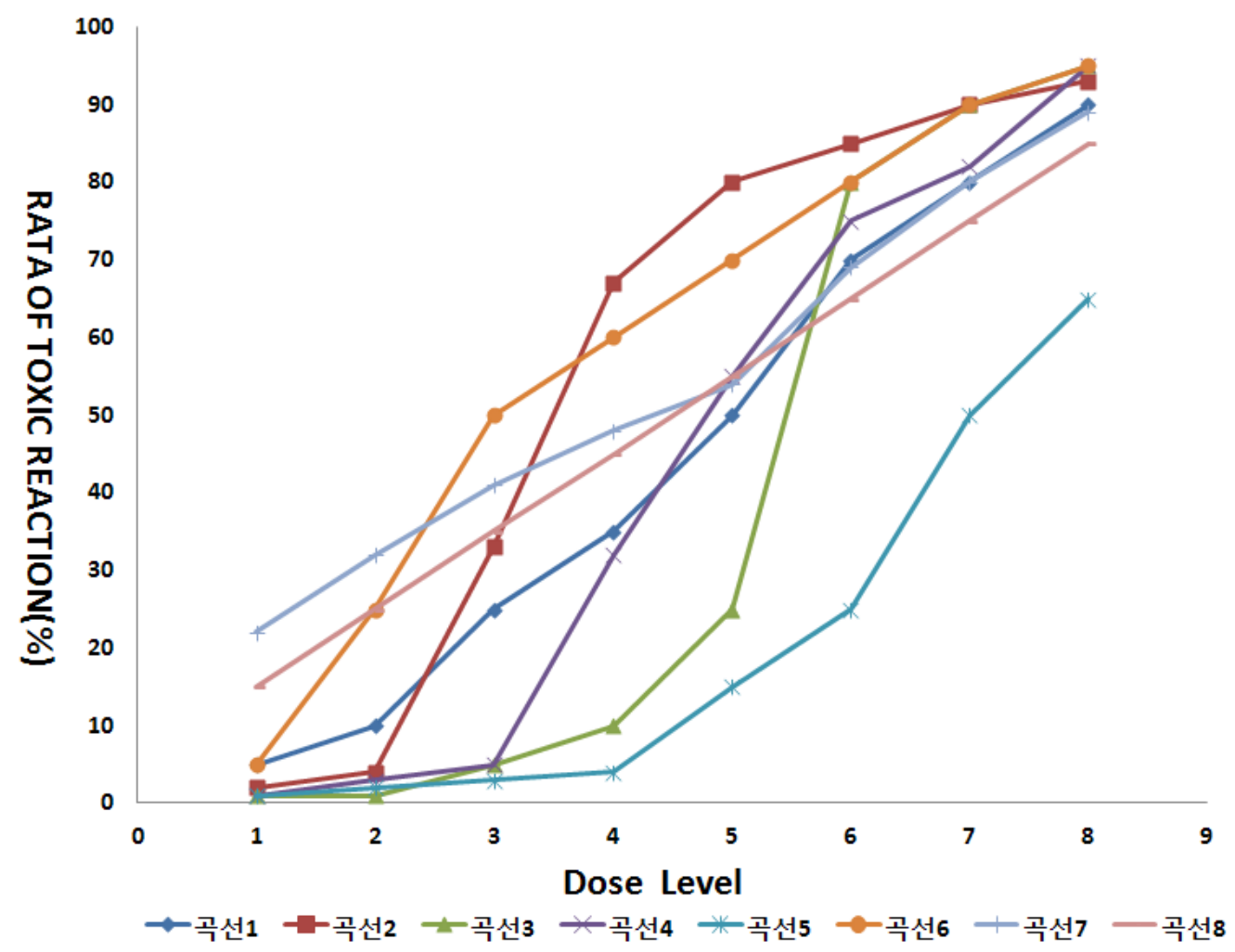

Figure 3.1. Dose toxicty curves

히 증가하는 경우, 곡선7과 8 은 처음 용량수준부터 이미 높은 독성 반응율을 보이는 경우이다.

모의실험에서 $\mathrm{BC} 4$ 방법은 Stopping Dose에 따라 표본 수가 달라지므로 시행에서 사용된 표본수의 평 균값을 제시하였고, $\mathrm{CRM}$ 방법은 사전에 미리 표본수를 정하는데 1상 임상실험에서는 보통 20 명 이하 의 작은 수의 피험자를 대상으로 실험이 이루어진다. 그래서 본 논문에서는 $\mathrm{BC} 4$ 방법에서 나온 표본 수 들의 평균값인 7 명을 $\mathrm{CRM}$ 방법에서 최대 피험자 수로 지정하고 모의실험을 실시하였다. 모의실험에 서 복용량 수준의 독성분포는 $\mathrm{SAS}$ 의 RANBIN함수를 사용하여 각 복용량 수준에 이항분포난수를 생 성하였다. 각 복용량 수준에 4 명의 피험자가 배정되는 $\mathrm{BC} 4$ 방법의 경우 $\operatorname{Bin}\left(1, p_{i j}\right)$ 로 난수를 발생하였 
Table 3.2. Number of subjects and estimate the ratio of MTD

\begin{tabular}{|c|c|c|c|c|c|c|c|c|c|c|c|c|}
\hline \multicolumn{10}{|c|}{$\begin{array}{c}\text { MTD의 추정비율과 피험자수 } \\
\theta=0.25\end{array}$} & & \multirow{2}{*}{$\begin{array}{l}\text { 독성반응 } \\
\text { 평균횟수 }\end{array}$} & \multirow{2}{*}{$\begin{array}{c}\text { 평균 } \\
\text { 피험자수 }\end{array}$} \\
\hline & Dose & 1 & 2 & 3 & 4 & 5 & 6 & 7 & 8 & & & \\
\hline 곡선1 & & 5 & 10 & 25 & 35 & 50 & 70 & 80 & 90 & none & & \\
\hline \multirow{2}{*}{ BC4 } & $\%$ MTD & 16.12 & 46.38 & 28.15 & 8.63 & 0.72 & 0.00 & 0.00 & 0.00 & 440 & 2.8152 & \\
\hline & 선택된 피험자(\%) & 30.33 & 29.88 & 25.72 & 11.30 & 2.62 & 0.16 & 0.00 & 0.00 & & & 7.164 \\
\hline \multirow{2}{*}{ CRM } & $\%$ MTD & 7.80 & 30.10 & 25.10 & 15.60 & 15.30 & 5.10 & 0.00 & 1.20 & 0 & 2.38 & \\
\hline & 선택된 피험자(\%) & 26.77 & 22.09 & 23.44 & 15.84 & 8.00 & 2.96 & 0.89 & 0.00 & & & 7 \\
\hline 곡선2 & & 2 & 4 & 33 & 67 & 80 & 85 & 90 & 93 & none & & \\
\hline \multirow{2}{*}{ BC4 } & $\%$ MTD & 3.04 & 69.16 & 27.40 & 27.40 & 0.00 & 0.00 & 0.00 & 0.00 & 98 & 2.851 & \\
\hline & 선택된 피험자(\%) & 30.76 & 30.94 & 31.47 & 6.76 & 0.07 & 0.00 & 0.00 & 0.00 & & & 6.8534 \\
\hline \multirow{2}{*}{ CRM } & $\% \mathrm{MTD}$ & 1.20 & 22.20 & 70.60 & 4.20 & 1.20 & 0.60 & 0.10 & 0.00 & 0 & 1.697 & \\
\hline & 선택된 피험자(\%) & 17.74 & 32.81 & 33.11 & 12.66 & 2.97 & 0.60 & 0.09 & 0.00 & & & 7 \\
\hline 곡선3 & & 1 & 1 & 5 & 10 & 25 & 80 & 90 & 95 & none & & \\
\hline \multirow{2}{*}{ BC4 } & $\%$ MTD & 0.19 & 4.21 & 14.54 & 44.69 & 36.27 & 0.11 & 0.00 & 0.00 & 18 & 3.1535 & \\
\hline & 선택된 피험자(\%) & 19.48 & 19.44 & 20.04 & 19.73 & 17.18 & 4.14 & 0.00 & 0.00 & & & 9.0029 \\
\hline \multirow{2}{*}{ CRM } & $\%$ MTD & 0.90 & 0.00 & 9.80 & 12.40 & 74.30 & 0.00 & 2.60 & 0.00 & 0 & 1.20 & \\
\hline & 선택된 피험자(\%) & 17.17 & 15.10 & 17.61 & 17.53 & 21.80 & 10.79 & 0.00 & 0.00 & & & 7 \\
\hline 곡선4 & & 1 & 3 & 5 & 32 & 55 & 75 & 82 & 95 & none & & \\
\hline \multirow{2}{*}{$\mathrm{BC} 4$} & $\%$ MTD & 1.68 & 4.44 & 66.05 & 26.57 & 1.25 & 0.00 & 0.00 & 0.00 & 29 & 2.8526 & \\
\hline & 선택된 피험자(\%) & 23.21 & 23.53 & 23.50 & 23.48 & 6.07 & 0.21 & 0.00 & 0.00 & & & 7.9532 \\
\hline \multirow{2}{*}{ CRM } & $\%$ MTD & 0.70 & 0.21 & 28.80 & 51.30 & 9.60 & 6.20 & 1.30 & 0.00 & 0 & 1.419 & \\
\hline & 선택된 피험자(\%) & 17.17 & 16.01 & 25.09 & 24.90 & 11.79 & 3.99 & 1.06 & 0.00 & & & 7 \\
\hline
\end{tabular}

다. 이때의 $p_{i j}$ 는 Table 3.1 에 곡선 $j(j=1,2, \ldots, 8)$ 의 $i(i=1,2, \ldots, 8)$ 번째 복용량의 독성율이다. $\mathrm{CRM}$ 방법은 R-package dfcrm을 이용하여 모의실험을 실시하였다. 멈춤규칙은 적용되지 않았고, 독성 모델은 제 1상 임상시험에서 자주 사용되고 있는 logistic 함수를 사용하였다. 초기에 추측되는 독성률 은 곡선 1 를 사용하였다. 목표독성확률은 $25 \%$ 으로 지정하고, 각 모의실험은 10,000 번 반복시행하였다. Table 3.2와 Table 3.3은 각 방법으로 모의실험한 결과로 각 방법별 MTD가 선택된 비율과 해당용량에 서 피험자가 모의실험에서 선택된 비율을 나타내고, 독성반응의 평균횟수도 나타낸다.

각 곡선의 선택된 피험자 $(\%)$ 를 곡선 1 , 곡선 3 , 곡선 5 , 곡선 6 , 곡선 8 에서 비교할 때 목표독성확률 $25 \%$ 보 다 높은 독성율에 할당된 선택된 피험자 $(\%)$ 가 $\mathrm{BC} 4$ 방법이 $\mathrm{CRM}$ 방법보다 더 적다. 목표독성확률이 곡 선 2 의 $33 \%$, 곡선 4 과 곡선 7 의 $32 \%$ 보다 높은 독성율에 할당된 경우에 선택된 피험자 $(\%) \mathrm{BC} 4$ 방법이 $\mathrm{CRM}$ 방법보다 더 적다. 이것은 $\mathrm{BC} 4$ 방법이 $\mathrm{CRM}$ 방법보다 안정성에서 우월하다는 것을 의미한다. 목 표독성확률 $25 \%$ 에 가깝게 $\mathrm{MTD}$ 를 추정하는 정확성에서는 곡선1과 곡선 8 에서는 $\mathrm{BC} 4$ 방법이 우월하지 만 나머지 곡선에서는 $\mathrm{CRM}$ 방법이 우월하다. 각 곡선의 용량별 $\mathrm{MTD}$ 가 선택되는 비율(\%)에서 목표독 성확률 $1 \%$ 에서 $25 \%$ 까지의 할당된 것을 비교했을 때 곡선 2 를 제외하고 $\mathrm{BC} 4$ 방법이 $\mathrm{CRM}$ 방법보다 많 이 할당되어있다. 이는 $\mathrm{BC} 4$ 방법이 $\mathrm{CRM}$ 방법보다 독성에 더 민감하고 용량추정에 보수적이기 때문이 다. 독성반응 평균횟수는 $\mathrm{BC} 4$ 방법 (2.83)이 $\mathrm{CRM}$ 방법(1.65)보다 높지만, 전체 곡선의 독성율반응의 범 위는 $\mathrm{BC} 4$ 방법 $(2.60,3.15)$ 이 $\mathrm{CRM}$ 방법 $(0.79,2.38)$ 보다 중심근처에 집중되어있다. Dose1에서 독성반 응이 발생해 실험을 진행할 수 없을 경우와 최고용량수준인 Dose8에 도달하여 더 이상 용량증가할 수 없는 경우를 경계선조건에 해당하는 경우이다. 이 때 $\mathrm{MTD}$ 추정이 불가능한 값이 결측값이다. $\mathrm{BC} 4$ 방 법의 경우 멈춤규칙을 이용한 방법이므로 결측값이 생기지만 $\mathrm{CRM}$ 방법의 경우 미리 고정된 피험자 수 
Table 3.3. Number of subjects and estimate the ratio of MTD

\begin{tabular}{|c|c|c|c|c|c|c|c|c|c|c|c|c|}
\hline & & MTD & $\begin{array}{r}\text { 추정ㅂ } \\
\theta=\end{array}$ & $\begin{array}{l}\text { |율과 표 } \\
0.25\end{array}$ & 기험자수 & & & & & & $\begin{array}{l}\text { 독성반응 } \\
\text { 펴규회스 }\end{array}$ & $\begin{array}{c}\text { 평균 } \\
\text { 미허 잣ㅅ }\end{array}$ \\
\hline & Dose & 1 & 2 & 3 & 4 & 5 & 6 & 7 & 8 & & & \\
\hline 곡선5 & & 1 & 2 & 3 & 4 & 15 & 25 & 50 & 65 & none & & \\
\hline $\mathrm{BCA}$ & $\%$ MTD & 0.78 & 1.48 & 3.33 & 27.11 & 36.26 & 28.39 & 2.65 & 0.00 & 22 & 3.0184 & \\
\hline Bし 4 & 선택된 피험자(\%) & 16.38 & 16.52 & 16.53 & 16.40 & 16.73 & 12.03 & 5.04 & 0.38 & & & 10.0109 \\
\hline & $\%$ MTD & 0.40 & 0.40 & 0.60 & 13.90 & 11.10 & 46.20 & 0.00 & 27.50 & 0 & 0.79 & \\
\hline & 선택된 피험자(\%) & 16.21 & 15.04 & 15.20 & 16.83 & 17.61 & 10.96 & 8.14 & 0.00 & & & 7 \\
\hline 곡선6 & & 5 & 25 & 50 & 60 & 70 & 80 & 90 & 95 & none & & \\
\hline $\mathrm{PC} 4$ & $\%$ MTD & 55.11 & 41.28 & 3.53 & 0.08 & 0.00 & 0.00 & 0.00 & 0.00 & 477 & 2.7451 & \\
\hline DU4 & 선택된 피험자(\%) & 40.82 & 41.14 & 16.74 & 1.27 & 0.02 & 0.00 & 0.00 & 0.00 & & & 6.095 \\
\hline & $\%$ MTD & 24.30 & 53.40 & 12.90 & 6.00 & 2.70 & 0.06 & 0.10 & 0.00 & 0 & 1.832 & \\
\hline & 선택된 피험자(\%) & 36.24 & 37.13 & 16.34 & 7.07 & 2.53 & 0.60 & 0.10 & 0.00 & & & 7 \\
\hline 곡선7 & & 22 & 32 & 41 & 48 & 54 & 69 & 80 & 89 & none & & \\
\hline $\mathrm{PCA}$ & $\%$ MTD & 69.34 & 25.90 & 4.28 & 0.46 & 0.46 & 0.00 & 0.00 & 0.00 & 4769 & 2.6068 & \\
\hline & 선택된 피험자(\%) & 58.95 & 30.56 & 9.07 & 1.31 & 0.12 & 0.00 & 0.00 & 0.00 & & & 5.3983 \\
\hline$M$ & $\%$ MTD & 55.90 & 19.30 & 7.50 & 7.10 & 5.20 & 4.50 & 0.00 & 0.50 & 0 & 2.088 & \\
\hline & 선택된 피험자(\%) & 56.34 & 21.80 & 10.20 & 6.53 & 3.70 & 1.07 & 0.34 & 0.00 & & & 7 \\
\hline 곡선8 & & 15 & 25 & 35 & 45 & 55 & 65 & 75 & 85 & none & & \\
\hline & $\% \mathrm{MTD}$ & 54.33 & 33.97 & 10.07 & 1.49 & 0.14 & 0.00 & 0.00 & 0.00 & 2902 & 2.6697 & \\
\hline & 선택된 피험자(\%) & 46.99 & 33.63 & 15.12 & 3.75 & 0.46 & 0.04 & 0.00 & 0.00 & & & 5.953 \\
\hline & $\%$ MTD & 40.40 & 20.20 & 14.80 & 14.90 & 3.00 & 5.80 & 0.00 & 0.90 & 0 & 1.817 & \\
\hline & 선택된 피험자(\%) & 46.03 & 25.51 & 12.61 & 8.90 & 5.03 & 1.40 & 0.51 & 0.00 & & & 7 \\
\hline
\end{tabular}

를 통해 피험자 한 명씩을 시험하는 방법이므로 결측값이 생기지 않는다.

\section{4. 결론 및 고찰}

제 1 상 임상시험은 사람을 대상으로 처음 실시하며, 신약후보물질의 안전성을 평가하고 약물동력학 및 약력학을 연구하기 위해 환자들을 대상으로 독성 및 부작용 등 반응을 관찰하는 단계이다. 제 1 상 임상 시험의 목적은 제 2 상 임상시험에 사용될 신약의 용량을 결정하는 일이며 적은 기간 동안에 소수의 피험 자와 높은 안정성으로 정확한 $\mathrm{MTD}$ 를 결정하는 방법이 제 1 상 임상시험에서 가장 적절한 방법이 된다.

본 논문에서는 기존의 제 1 상 임상시험에서 많이 사용하고 있는 표준방법이며 멈춤 규칙을 이용하며 독 성발생확률이 $33 \%$ 에 가까울 것이라는 막연한 추측을 기반으로 한 SM3방법을 응용해 $\mathrm{BC} 4$ 방법을 제안 하였다. 그리고 같은 목표독성확률 $25 \%$ 를 기반으로 한 $\mathrm{BC} 4$ 방법과 $\mathrm{CRM}$ 방법을 8 개의 다양한 독성발 생곡선에서 비교 모의실험을 실시하였다. $\mathrm{CRM}$ 방법은 이전의 환자로부터 얻어진 독성결과를 이용해, 이전에 가지고 있던 용량 독성 곡선에 대한 정보를 수정하여 다음 환자에게 투여할 용량을 정하는 축차 적인 방법이다.

이 모의실험의 결과로 $\mathrm{BC} 4$ 방법은 $\mathrm{CRM}$ 방법에 비해 목표독성확률 $25 \%$ 보다 높은 독성율에 할당된 선 택된 피험자 $(\%)$ 값이 낮으므로 안전성에서 $\mathrm{BC} 4$ 방법이 $\mathrm{CRM}$ 방법보다 우월하다. 또한 독성반응에 민 감한 $\mathrm{BC} 4$ 방법은 $\mathrm{CRM}$ 방법에 비해 목표독성확률 $25 \%$ 보다 낮은 곳에 $\mathrm{MTD} \%$ 값이 많이 나왔으므로 $\mathrm{MTD}$ 추정에 보수적이다. 그리고 $\mathrm{CRM}$ 방법은 앞선 피험자의 반응에게서 얻어진 독성결과를 이용해 다 음 피험자에게 투여할 용량을 결정해야하므로 시간이 지나치게 많이 소요되며 매 시험마다 복잡한 계산 
을 해야 하는 문제점으로 시험자는 쉽게 사용하지 못하지만, $\mathrm{BC} 4$ 방법은 이에 비해 단순하고 쉽게 사용 할 수 있는 장점이 있다. 그러나 $\mathrm{BC} 4$ 방법은 $\mathrm{CRM}$ 방법에 비해 정확성이 낮으며, 독성반응에 민감하고 보수적이기 때문에 독성반응평가횟수가 높은 단점이 있다. 또한 $\mathrm{BC} 4$ 방법은 $\mathrm{CRM}$ 방법에 비해 용량증 가가 느리고 결측치가 발생하기 때문에 보완이 필요하다.

\section{References}

Ahn, C. (1998). An evaluation of phase I cancer clinical trial designs, Statistics in Medicine, 17, 1537-1549.

Chevret, S. (1993). The continual reassessment method in cancer phase I clinical trials: A simulation study, Statistics in Medicine, 12, 1093-1108.

Dixon, W. J. and Mode, A. M. (1948). A method for obtaining and analyzing sensitivity data, Journal of the American Statistical Association, 43, 109-126.

Faries, D. (1994). Practical modifications of the continual reassessment method for phase 1 cancer clinical trials, Journal of Biopharmaceutical Statistics, 4, 147-164.

Goodman, S. N., Zhurak, M. L. and Piantadosi, S. (1995). Some practical improvements in the continual reassessment method for phase I studies, Statistics in Medicine, 14, 1149-1161.

Kang, S. H. (2002). Investigation on the modified continual reassessment method in phase I clinical trial, Journal of Applied Statistics, 15, 323-336.

Kim, D. U. and Kil, S. K. (2009). Precision and safety comparison for SM, CRM and ATD in phase I clinical trials, Communications of the Korean Statistical Society, 16, 51-65.

Korn, E. L., Midthune, D., Chen, T. T., Rubinstein, L. V., Christian, M. C. and Simon, R. M. (1994). A comparison of two phase I trial designs, Statistics in Medicine, 13, 1799-1806.

O'Quigley, J. and Chevret, S. (1991). Method for dose finding studies in cancer clinical trials: A review and results of a Monte Carlo study, Statistics in Medicine, 10, 1647-1664.

Park, I. H. (1999). The estimation of maximal tolerated dose in sequential phase I clinical trials, Department of Biostatistics, The Catholic University of Korea, Biostatistics Master's Thesis.

Storer, B. E. (1989). Design and analysis of phase I clinical trials, Biometrics, 45, 925-937. 


\title{
제 1상 임상시험에서 멈춤 규칙과 SM3 디자인을 이용한 최대허용용량 추정법
}

\author{
김병찬 ${ }^{a} \cdot$ 김동재 $^{a, 1}$ \\ ${ }^{a}$ 가톨릭대학교 의학통계학과
}

(2013년 10월 15일 접수, 2013년 11월 15일 수정, 2013년 11월 15일 채택)

$$
\text { 요 약 }
$$

제 1 상 임상시험의 목적은 피험자가 견딜 수 있는 최대의 용량인 최대허용용량(Maimum Tolerated Dose; $\mathrm{MTD}$ )을 추정하는 것이다. 최대허용용량을 추정하는 방법으로는 SM방법, ATD방법, CRM방법 등이 있다. 본 연 구에서는 제 1 상 임상시험에서 멈춤규칙을 이용한 최대허용용량 추정법을 제안하였다. 제안한 최대허용용량 추정법 은 연속재평가방법(Continual Reassessment Method; CRM)과 모의실험을 통해 비교하였다.

주요용어: 제 1 임상시험, 최대허용용량, 멈춤 규칙. 